\title{
The European Infantryman's Rifle
}

\author{
Comparison of Mausers, Mannlichers, Lee- // Enfields, and Other Weapons Used in the War \\ By Edward \\ On the Whole the Great Military Powers Agree \\ in the Demands They Make of the Service \\ Rifle. England Seems to be the Worst \\ Off, Because Her Troops Are Not \\ Uniformly Armed \\ C. Crossman \\ As Might be Expected the German Mauser \\ is the Best Servited \\ It has Been Adopted by Other Fighting \\ Nations, Notably Belgium, Turkey, \\ and Russia
}

THE British were caught in bad shape when the war broke out. They have clung to the old Lee action. taken up in 1889 , and with many changes have used it ever since despite its weakness and the advent of better rifles. Evidently the hope of an automatic military rifle prevented them from disarming their troops of the old Lee and re-arming them with a better rifie, like the Ross or Mauser.

They now use the short Lee-Enfield in the regular army which is now on the Continent, a rifle using chargers of five cartridges something like the clip of the Mauser, for refilling the Mauser magazine. Only the British rifle, having a protruding box magazine, holds ten cartridges or two clips at a time, against the five of nearly all other rifies like the Mauser and its American brother, the new Springfield, a Mauser with American brothe
scme changes.

Unhappily the territorials, or "militia," as we would call them, have the older long rifle, giving different shooting, and of course a nuisance were two forces of the two branches fighting on the same line. Both rifles are inferior in strength and simplicity to the Mauser. The British had an experimental rifle finished and a few ready for experimental issue when the war brokea Mauser firing the 0.280 cartridge much like the Ross. Of course, it cannot be used, not being beyond the experimental stage.

The British Mix Their Rifles and Ammunition.

Worse still, the British have a mixed lot of ammunition, and this might cause bad mixups in giving sight settings and calculating the fire of troops. The regulurs on the Continent are using the Mark VII, a spitzer of 174 grains loaded into the same old 0.303 case, but gîning 2,440 foot-seconds instead of 2,000 , as did the old Mark VI, with blunt nose 215-grain bullet. This Mark Mark VI, with blunt nose 215-grain bullet. This Mark
VII is a fair cartridge, but there is not enough of it and the British must fall back upon the Mark VI old style stuff, giving lower velocity; and worse than this, to be shot in rifles sighted and with sights graduater for the newer ammunition.

Take, for example, a regiment of the line, armed like the others with the short Lee, but supplied in the rush of a hot attack with the Mark VI or old ammunition. If the officers giving range and sight settings did not know and remember this and give a far higher sight setting to compensate for the lower speed of the old style stuff, the entire fire of this regiment would be wasted, because the bullets would strike the ground short of the mark. Mixed ammunition, like mixed rifies, is a frightfully bad thing in hard fighting.

The Mark VII is loaded with 40 grains of tubular The Mark VII is loaded with 40 grains of tubular
cordite powder, a yellow, celluloid-like stuff that comes in tubes or sticks just the length of the shell space behind the bullet. A bundle of the sticks is pushed into the cartridge, then the neck is formed by machinery and the bullet seated in this neck.

The British have bought a huge number of the Japanese service rifie, a modified Mauser manufactured in Japanese arsenals, but fear to send them to the Continent because of the great complications they would add to the already hard problem of supplying the right ammunition for the various types of rifles their troops already are using. Unless a complete unit, such as a division, can be armed with these rifles, sending them over would merely add trouble. The Japanese rifie is 0.25 caliber; the British rifie is a 0.303 .

Very evidently the British have been badly blistered by the work of the despised German sharpshooters, and they lay most of the efficiency of these men to their telescopic rifle sights.

A number of men in every German company of infantry are supplied with the fine prismatic telescopic rifle sights, and with these to aid them in picking up, and aligning the rifles upon almost hidden foes, they do murderous work in their sniping.

The British have finally resolved to meet them at their own game, and have placed large orders in
America for telescopic rifle sights, depending mostly upon the makers of the telescope sight for the American army. In our own service the two best shots in each company of infantry are armed with rifles equipped with fine prismatic telescope sights, for just this sniping work.

On a well-lighted and defined objective, the telescope rifle sight offers no advantage to the man with normal eyesight, but in picking out a partly hidden or badly lighted mark, the telescope sight gives the rifleman the same advantage that a fine prismatic field glass gives the person using it. It is necessary merely to find the mark in the field of the glass, touch it with the needle point in the telescope field and squeeze the trigger.

The telescope mounted on the American service rifie, although not yet perfect, is probably the most carefully designed telescopic sight ever made. Short and compact, it is furnished with graduated elevating and traversing disks for the finest adjustments in range and windage. No other instrument of its sort approaches it, save the sighting telescopes used on field guns. Optically, it is hardly the equal of the German glasses.

The French "Lebel"-An Amusing Rifle. The French use a rifle, the Lebel, that looks like the old wrecks sold in department and army sale stores, and labeled Veterli or something similar to it. It has a tubular magazine in the forestock like an American repeating rifle, the receiver is nickel-plated, and, all in all, it is the most amusing looking rifle of the whole collection. Its whole get-up looks crude and child-like. Add to this a fearfully long triangular bayonet, such as the American army discarded twenty years ago, give the soldier carrying it a long blue coat like an overcoat and a pair of red trousers, and you've got a picture to make the gods weak from laughter.

The cartridge is quite interesting, with its solid copper-zi ac alloy bullet. Not satisfied with the virtues of the sharp point, the French went still farther, and put on a tapering stern on their bullet; so it is a true boatshaped bullet, instead of being cut off square behind like all other bullets. Thus, the bullet is given a streamline form, which even German ballistic experts admit cuts down air resistance. It weighs 170 grains and it leaves the rifie with a speed of 2,400 foot-seconds. It is quite as good as the English cartridge. The magazine is loaded, not with clips or chargers like the rifles of the others, but by the slow process of cramming in one shell after another into a tubular magazine like an American Winchester's.

\section{The Russians and Their Modified Mauser.}

The Russians use a modified Mauser, with ammunition of the old blunt nose type like the British Mark VI, velocity 2,000 foot-seconds. The bayonet, a triangular one, is always fixed, is very hard to remove, and has no scabbard. It is carried on the rifle at all times-a very clumsy, crude and senseless scheme.

The Belgians use the Mauser, with ammunition of the older blunt nose type, clip-loading, like the rifles of all the nations save France. In this system a clip or charger of five cartridges is pushed into a slot at the top of the magazine entrance. A push of the thumb drives all five out of the clip, down into the magazine, and the clip is thrown away. The caliber, like that of the Russian and French rifles, is practically 0.30 The Turks use the Mauser, of 0.30 caliber, and use to some extent the newer pointed bullets in this rifle.

The Austrians and the Germans are the best equipped of any of the nations in the rifle line. The Austrians use the Mannlicher, firing pointed bullets with a velocity of nearly 2,800 foot-seconds.

The New German Mauser-The Best in Europe. The Germans use the latest type of Mauser, from which the American new Springfield was taken. The rifle, a clip-loader, weighs nine pounds. It fires spitzer bullets of 154 grains weight, with a velocity of -over 2,900 foot-seconds. The rifle in its simple sight-setting arrangement, its finish, its accuracy, and the high speed of its bullet is superior to the rifie of any other nation among those fighting. It has a long sword bayonet, usually carried in a scabbard at the soldier's belt. With its long barrel and long bayonet, it gives a stabbing length of 5 feet 9 inches with the bayonet on, beating the others save the long bayonet of the Frenchman. The German soldier has eight inches the better of the argument over the British soldier when it comes to crossing bayonets, and the extra eight inches easily turns the battle in favor of the longer, if both men are of equal skill.

The Japanese, in true Japanese style, a people who lift everything they fancy and make it without regard to the laws of patents or copyright, make a rifle that is a Mauser in the points that are good, terming it "Year 38." It fires a 0.25 caliber cartridge, with pointed bullet and a velocity of 2,900 foot-seconds.

The Canadians, in spite of being part of the forces of the British Empire, cast out the ancient and honorable Lee nearly ten years ago, taking the Ross, a rifie made by Sir Charles Ross of Scotland, in Quebec. Their present rifle, practically the rifle that sells on the American market for sporting use, fires the regulation 0.303 British army cartridge instead of the much better Ross product, the 0.280 . This, of course, because of the necessity for using the same cartridge as the British troops.

This Ross is a straight pull rifle; that is, by an arrangement primarily like the familiar spiral screwdriver, the bolt with the locking lugs is revolved by pulling straight back on a bolt handle and separate sleeve, unlocking the bolt without the usial half turn of a bolt handle, as on the Mauser, Krag, new Springfield, and Lee-Enfield.

The Rifles of Austria, Bulgaria and Greece. The same principle is used in the Mannlicher straight pull of Austria, Bulgaria, and Greece. This type of rifle action is very fast, a snap back and forth of the wrist being sufficient to operate it, but it is more tiring for a long series of shots because of throwing the strain on only one set of muscles.

All the other rifles use what is called the turn-bolt, a long cylindrical bolt containing striker and main spring, carrying an extractor on the head, and having two steel lugs to lock against the explosion, working back and forth in grooves cut in the receiver. The bolt is locked by turning it a quarter round to the right, revolving the lugs in behind shoulders in the frame; it is unlocked in the reverse direction, hence the hame turn-bolt, as opposed to the straight pull rifles of Austria, Greece, Bulgaria, Switzerland, and Canada. The chief virtues of these rifies is the strength, the simplicity, and the impossibility of jamming the mechanism for more than a moment. All the essential parts can be removed for cleaning and repairs without tools.

This is true in the highest degree with the German Mauser, in the lowest with the French Lebel and the straight pull Mannlichers.

With these magazine rifies, fitted with magazines for charger loading, and having a wonderfully high rate of sustained fire, the problem is to keep the men supplied with ammunition for an all-day's hot battle. The Japanese troops went into some of the battles near the Yalu and later, carrying 350 rounds of ammunition per man. Yet some of the soldiers were out of cartridges by noon. The weight of 350 rounds of the Japanese 0.256 cartridge is, of course, 350 times the weight of each cartridge, this being 350 grains. Each soldier was therefore carrying, besides his regular pack and rifie, $171 / 2$ pounds of cartridges.

The British soldier, carrying as much, is still worse loaded down, because of the greater weight of his ammunition. Using the old type of Mark VI, to which he is probably reduced by this time, he lugs nearly 21 pounds if he takes in 350 rounds. With hasty trenches thrown within 400 yards of each other, as reported in one phase of the British fighting, there is very little time to replenish the supply on the firing line from the reserve store as is laid down by all good text books 